\title{
Laparoendoscopic Single-Site Bariatric Surgery: A Review of Single-Port Laparoscopic and Endoscopic Bariatric Treatments
}

\author{
So Hyun Kang ${ }^{1}$, Young Suk Park', Sang-Hoon Ahn ${ }^{1,2, *}$, Do Joong Park ${ }^{1,2}$, Hyung-Ho Kim ${ }^{1,2}$ \\ 'Department of Surgery, Seoul National University Bundang Hospital, Seongnam; '2Department of Surgery, Seoul National University College of Medicine, Seoul, \\ Korea
}

Bariatric surgery is an established and effective treatment, not only to combat morbid obesity, but also to address associated metabolic comorbidities. At this time, the cutoff for bariatric or metabolic surgery in terms of body mass index (BMI) is decreasing, making it more feasible for certain individuals to consider minimally invasive surgical options. Innovations in the technique have led to the application of laparoendoscopic single-site surgery (LESS) in the field of bariatrics, which uses a single or no incision in the performance of weight-reducing surgery. To date, there is no consensus regarding patient selection though most candidates for single-port bariatric surgery are female. Some doctors suggest that single-port bariatric surgery may not be recommended in patients with BMl of more than $50 \mathrm{~kg} / \mathrm{m}^{2}$, height of more than $180 \mathrm{~cm}$, and xiphoid-umbilicus distance of more than $20 \mathrm{~cm}$. Sleeve gastrectomy (SG) is now the most widely performed bariatric surgery worldwide and singleport SG (SPSG) is already established as a routine procedure in various institutions. Current evidence shows that SPSG is less painful and demonstrates higher rates of patient satisfaction regarding the wound. SPSG is feasible and is recommendable in patients who meet certain criteria. Furthermore, endoscopic treatment modalities such as intragastric balloons and endoluminal malabsorptive devices are being developed to bridge the gap between medical and surgical treatments. Nevertheless, there is still insufficient evidence to prove the superiority of LESS bariatric surgery over conventional laparoscopic surgery. Large, well-designed prospective analyses are needed to determine the criteria for selecting patients suitable to undergo LESS bariatric surgery and to predict the procedure's role in the growth of bariatric surgery.

Key words: Bariatric surgery, Obesity, Laparoscopy, Endoscopy

\author{
Received January 31, 2018 \\ Reviewed February 12, 2018 \\ Accepted February 23, 2018 \\ *Corresponding author \\ Sang-Hoon Ahn
}

(iD)

https://orcid.org/0000-0001-8827-3625

Department of Surgery, Seoul National University Bundang Hospital, Seoul

National University College of Medicine, 82 Gumi-ro 173beon-gil, Bundang-gu,

Seongnam 13620, Korea

Tel: +82-31-787-7106

Fax: +82-31-787-4078

E-mail: viscaria@snubh.org

\section{INTRODUCTION}

Morbid obesity has been an increasingly serious medical issue for decades, with recent studies indicating the growing need for surgical treatment in affected individuals. Currently, bariatric surgery is the most effective treatment for morbid obesity and its associated comorbidities, providing faster body weight reduction and better glycemic control as compared with traditional medical therapies. $^{1-3}$ The most commonly performed surgical therapies include adjustable gastric banding (AGB), sleeve gastrectomy (SG), Rouxen-Y gastric bypass (RYGB), and biliopancreatic diversion (BPD) surgery. Laparoscopic surgery was initially applied in conjunction with AGB starting in the early 1990s. ${ }^{4}$ Now, many of these procedures are being performed laparoscopically, providing better cosmesis and a weight loss rate of more than 50\% in long-term studies. $^{2,5,6}$ As technology and innovation in the surgical field continue to evolve, more minimally invasive methods are being developed. Procedures such as reduced port laparoscopic surgery and even

Copyright (C) 2018 Korean Society for the Study of Obesity

(ㄷ) This is an Open Access article distributed under the terms of the Creative Commons Attribution Non-Commercial License (http://creativecommons.org/licenses/by-nc/4.o/) which permits unrestricted non-commercial use, distribution, and reproduction in any medium, provided the original work is properly cited. 
single-incision laparoscopic surgery (SILS) are now being completed worldwide as bariatric procedures. ${ }^{7,8}$ Single-incision transumbilical surgery uses the umbilicus as the only port-site and is considered to be a bridge to natural orifice transluminal endoscopic surgery, due to having a similar cosmetic outcome whilst enabling the use of conventional laparoscopic instruments. ${ }^{8,9}$ The ultimate goal of any bariatric procedure is scarless, painless surgery, and advancements in this area are growing faster than ever before.

With the escalating number of single-incision surgeries among various surgical disciplines, the term "laparoendoscopic single-site surgery" (LESS) was discussed during the 2008 meeting of the Laparoendoscopic Single-Site Surgery Consortium for Assessment and Research ${ }^{10}$ to provide a consistent and precise nomenclature for its principles. LESS encompasses concepts regarding single-entry port laparoscopic or robotic surgery as well as endoscopic surgery. There are some reviews that have been published to date regarding the application of reduced port or single-incision surgery for the treatment of morbid obesity ${ }^{8,11}$, but none have encompassed both endoscopic and laparoscopic approaches. This review aims to address and summarize LESS treatment modalities for morbid obesity and to describe some of the experiences in our center.

\section{PRIMARY TECHNIQUE}

Conventional laparoscopic bariatric surgery employs five to eight incisions for trocar placement. Due to the thickness of the abdominal wall in obese patients, a small incision creates a "fulcrum effect," which hinders range of motion. ${ }^{12}$ Hence, the incision must be made in a larger fashion in obese patients so as to avoid this effect. Reduced port laparoscopic surgery refers to laparoscopic surgery with less than the traditional number of port incisions. Most often, two to three incisions are made during reduced port surgery. The liver must be then retracted upward to provide the surgical field of view for bariatric surgery. In multiport laparoscopic procedures, the liver can be lifted with the help of another operator or assistant using a second port. However, in SILS, the collision of instruments and lack of space makes the use of an assistant impossible. Huang et al. ${ }^{13}$ reported a method of "liver suspension tape," which uses a modified Jackson-Pratt drain tube and involves needle penetration to lift the liver. Saber et al. ${ }^{14}$ noted the high incidence of fatty liver in obese patients and used transdiaphragmatic sutures for traction. In some morbidly obese patients, the insertion of a liver retractor through a 5-mm subxiphoid puncture was necessary. In our center, we typically use the combined suture retraction ${ }^{15}$ for most, if not all, of our cases. Proper retraction of the liver is crucial in successfully securing the surgical field of view and in competently performing SILS.

\section{LAPAROSCOPIC PROCEDURES}

\section{Single-port adjustable gastric banding}

Gastric banding is the first reported example of LESS bariatric surgery, with the first known procedure performed by Nguyen et al. ${ }^{16}$ in 2008. Despite the lower rate of weight loss seen with gastric banding in comparison with that accompanying other surgical procedures, it still remains a popular procedure, since there is no need to perform a resection or anastomosis of the gastrointestinal tract. ${ }^{2}$ In AGB, a pars flaccida approach is used to place a synthetic band around the proximal cardia. Since its first attempt, several cases of single-port AGB (SP-AGB) have been reported. A few comparative studies have shown that SP-AGB has a similar or even faster typical operative time versus that of conventional laparoscopic AGB. ${ }^{17,18}$ However, reports of complications - even life-threatening onesafter gastric banding have been increasing. A report of 1,000 cases by Chevallier et al. ${ }^{19}$ showed a complication rate of $19.2 \%$, while Suter et al. ${ }^{20}$ found a $40 \%$ of 5 -year failure rate and a $43 \%$ of 7 -year success rate. Although AGB may seem an ideal technique for single-port surgery due to its less-invasive nature, its practice is decreasing throughout the world due to associated surgical complications and reoperation rates.

\section{Single-port Roux-en-Y gastric bypass}

Recent trends have shown a decrease in the number of RYGB operations, yet it remains one of the most performed bariatric surgeries in the world, being mostly actively performed at this time in Latin America. ${ }^{2,21}$ Obesity is often accompanied with metabolic diseases such as diabetes mellitus, and gastric bypass causes hormonal changes that enables better glycemic control. ${ }^{22,23}$ In RYGB, the stomach is transected to create a 25 to $30 \mathrm{~mL}$ volume of gastric pouch. It is then connected to the Roux limb of the jejunum. Due 
to its comparatively higher complexity, only a few reports of singleport RYGB (SP-RYGB) are available in the literature. Still, early case reports of SP-RYGB have shown it to be feasible and safe in the short-term follow-up. ${ }^{12,24} \mathrm{~A}$ systematic review by Doulamis and Economopoulos ${ }^{25}$ of 10 studies of transumbilical RYGB, including four cases of SP-RYGB, demonstrated an average operative time of 128.5 minutes (range, 60-240 minutes). Cosmesis was good, but rates of $1.2 \%$ for anastomosis leak and $1.2 \%$ for wound infection were present. The complication rates were comparable or even less than those seen with traditional laparoscopic RYGB. ${ }^{26,27}$ We previously reported a case of single-incision resectional gastric bypass using a scope holder. ${ }^{9}$ Due to the high incidence of gastric cancer in Korea, resectional RYGB is selectively being performed in our center after sufficient patient counseling is completed. Often, the specimen can be easily removed through a $3-\mathrm{cm}$ transumbilical incision. SP-RYGB requires more complex surgical skills as compared with SG, but it is still feasible and may be a suitable choice for patients with diabetes. More long-term studies and well-designed randomized trials are needed to fully provide evidence on this topic.

\section{Single-port sleeve gastrectomy}

According to the 2014 survey of the International Federation for the Surgery of Obesity and Metabolic Diseases, SG is now the most commonly performed bariatric surgery worldwide and is increasing in prevalence. ${ }^{21}$ In SG, the greater curvature of the stomach is mobilized and the stomach is transected vertically using gastrointestinal staplers. Most SG procedures are done laparoscopically in several institutions, and single-port SG (SPSG) is also actively being performed. ${ }^{28,29}$ Pourcher et al..$^{30}$ reported a series of 60 consecutive SPSG patients, with a median operating time of $86 \mathrm{~min}$ utes, and found no differences in weight loss or comorbidity between these individuals and those who had undergone conventional laparoscopic SG. Saber et al. ${ }^{14}$ reported on both the transabdominal and transumbilical single-port approaches for SG. As compared with multiport SG, SPSG showed no difference in operation time or blood loss and demonstrated a lower pain score and hospital stay length. A 2-year prospective study of 600 patients showed no differences in surgical outcome or excess weight loss between patients undergoing SPSG and those undergoing multiport SG. ${ }^{31}$ Lakdawala et al. ${ }^{31}$ composed a scar satisfaction score to assess cosmesis, and the SPSG group displayed significantly higher satisfaction. In this study, the need for analgesics after surgery was significantly less in the SPSG group. SG is also the most commonly performed bariatric surgery in our center and, most often, it is done with a single 2.5 to $3 \mathrm{~cm}$ transumbilical incision. The liver is retracted using the Prolene (Ethicon, Somerville, NJ, USA) suture method described earlier and automatic staplers are used to make the resection. Although studies show that gastric bypass allows for better glycemic control, according to a randomized study by Schauer et al. ${ }^{1}$, SG also has a significant effect on the treatment of diabetes as compared with medical therapy alone. The fact that SG is technically less demanding that RYGB, yet provides adequate control of body weight and combined metabolic disorders, makes it and especially SPSG the most preferred type of bariatric surgery in our department. To our knowledge, we are the only Korean institution to have contributed cases of SPSG to the literature. ${ }^{32}$ Fig. 1A shows the transumbilical wound immediately after the operation, while Fig. 1B shows the almost invisible surgical wound at 3 months postoperation. Fig. 2 is a sample of the extracted sleeve specimen in the routine SPSG performed in our department.

\section{Single-port biliopancreatic diversion}

BPD surgery is not a specific operation but rather a concept represented by a malabsorptive technique that requires the diversion of the gastric contents to delay its interaction with the digestive juice. BPD surgery can include distal gastrectomy or SG accompanied by jejunoileal bypass. It is also being routinely performed lapa-
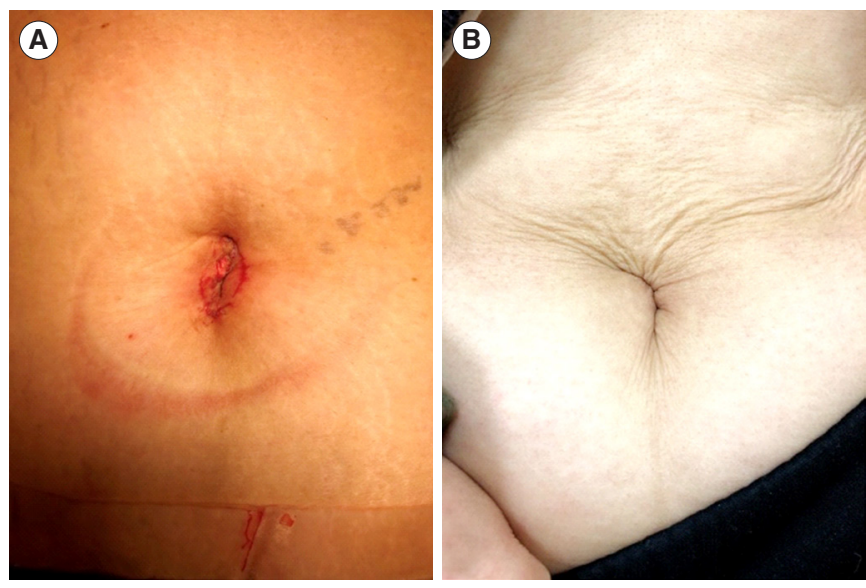

Figure 1. Surgical wound after single-port bariatric surgery. (A) Immediate postoperative wound. (B) Surgical wound after 3 weeks. 
roscopically ${ }^{33}$, and the first single-port BPD (SP-BPD) procedure was reported by Tacchino et al..$^{34}$ using the transumbilical approach. The operating time for this case was 130 minutes with no immediate postoperative complications. BPD is not often performed in our institution and it is only really considered in cases of extreme morbid obesity. Known reports of single-port bariatric procedures

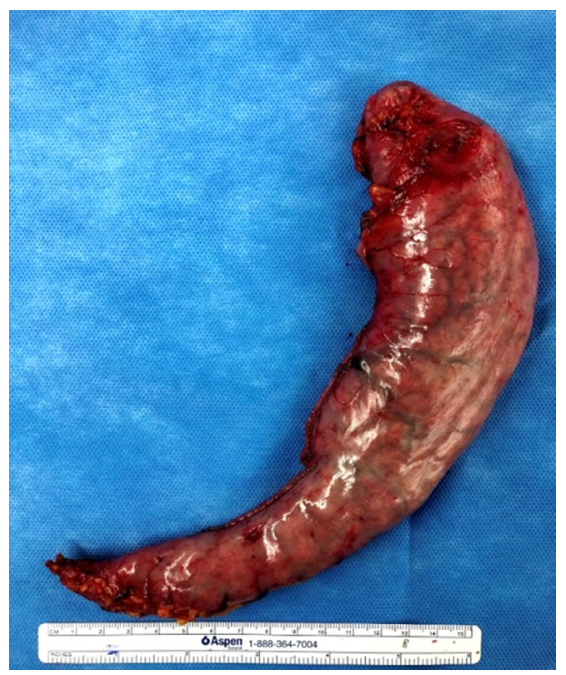

Figure 2. Extracted specimen after sleeve gastrectomy. are briefly summarized in Table $1.9,13,14,17,24,28,30,31,34-41$

\section{ENDOSCOPIC PROCEDURES}

\section{Intragastric balloon}

With the evolution of endoscopic and percutaneous procedures, patients who are mild to moderately obese are seeking methods that require no surgical intervention. Although the introduction of intragastric balloons occurred in $1980 \mathrm{~s}^{42}$, it was not until the early 1990s that the procedure became efficient and popular through the development of the BioEnterics intragastric balloon (BIB; Allergan, Dublin, Ireland), which is now currently known as the Orbera intragastric balloon (Apollo Endosurgery, San Diego, CA, USA) (Fig. 3). ${ }^{43}$ Studies employing the BIB reported stability with up to 6 months of use, with subsequent retrieval via endoscopy. A study of 2,515 patients with an average body mass index (BMI) of $44.4 \pm 7.8$ $\mathrm{kg} / \mathrm{m}^{2}$ showed a BMI reduction of $4.9 \pm 12.7 \mathrm{~kg} / \mathrm{m}^{2}$ after insertion of the BIB. ${ }^{44}$ Among the procedures, there were five cases $(0.19 \%)$ of gastric perforation and 19 cases $(0.76 \%)$ of gastric obstruction. A meta-analysis described the safety and effectivity of the BIB in

Table 1. A brief summary of major papers that have been published on the subject of single-port bariatric surgery

\begin{tabular}{|c|c|c|c|c|c|c|c|c|c|}
\hline Surgical procedure & Author & Year published & No. of cases & Incision & $\begin{array}{l}\text { Age } \\
\text { (yr) }\end{array}$ & $\begin{array}{c}\mathrm{BMl} \\
\left(\mathrm{kg} / \mathrm{m}^{2}\right)\end{array}$ & $\begin{array}{c}\text { Sex } \\
\text { (male:female) }\end{array}$ & $\begin{array}{l}\text { Operation time } \\
\text { (min) }\end{array}$ & $\begin{array}{c}\text { Complication } \\
\text { rate }(\%)\end{array}$ \\
\hline \multicolumn{10}{|c|}{ Adjustable gastric banding } \\
\hline & Teixeira et al. ${ }^{35}$ & 2009 & 10 & PU & 47.0 & 42.0 & $1: 9$ & 70.0 & 0 \\
\hline & Raman et al. ${ }^{36}$ & 2011 & 24 & TU & 39.7 & 41.7 & $0: 24$ & 62.6 & 0 \\
\hline & Patel et al. ${ }^{37}$ & 2012 & 111 & $\mathrm{TA}$ & 43.0 & 40.0 & $18: 93$ & 70.0 & 0 \\
\hline & Schwack et al. ${ }^{17}$ & 2013 & 710 & PU & 40.0 & 42.8 & $233: 477$ & 44.3 & 5.6 \\
\hline & Pitot et al. ${ }^{38}$ & 2014 & 34 & TU & 42.6 & 41.9 & $10: 24$ & 111.8 & 0 \\
\hline \multicolumn{10}{|l|}{ Sleeve gastrectomy } \\
\hline & Saber et al. ${ }^{14}$ & 2010 & 14 & TU & 44.2 & 53.8 & $7: 7$ & 128.0 & 0 \\
\hline & Pourcher et al. ${ }^{30}$ & 2013 & 60 & TU & 40.1 & 46.5 & $6: 54$ & 86.0 & 3.3 \\
\hline & Sucher et al. ${ }^{39}$ & 2014 & 40 & TU & 41.0 & 40.8 & $0: 40$ & 85.0 & 5.0 \\
\hline & Lakdawala et al. ${ }^{31}$ & 2015 & 300 & TU & 35.5 & 39.9 & $22: 278$ & 45.0 & 2.3 \\
\hline & Gaillard et al. ${ }^{28}$ & 2016 & 1,000 & $\mathrm{TA}$ & 40.1 & 42.6 & $155: 845$ & 112.0 & 14.7 \\
\hline \multicolumn{10}{|c|}{ Roux-en Y gastric bypass } \\
\hline & Huang et al. ${ }^{13}$ & 2010 & 25 & TU & 29.9 & 41.9 & $4: 21$ & 99.8 & 0 \\
\hline & Saber et al. ${ }^{24}$ & 2009 & 1 & TU & 34.0 & 38.7 & $0: 1$ & 133.0 & 0 \\
\hline & Morales-Conde et al. ${ }^{40}$ & 2013 & 22 & TU & 41.0 & 42.7 & $1: 21$ & 114.1 & 0 \\
\hline & Fernández et al. ${ }^{41}$ & 2013 & 3 & TU & 33.7 & 37.2 & $0: 3$ & 166.7 & 0 \\
\hline & Kang et al. ${ }^{9}$ & 2017 & 1 & TU & 22.0 & 44.9 & $1: 0$ & 160.0 & 0 \\
\hline \multicolumn{10}{|c|}{ Biliopancreatic diversion } \\
\hline & Tacchino et al. ${ }^{34}$ & 2010 & 1 & TU & 57.0 & 43.0 & $1: 0$ & 139.0 & 0 \\
\hline
\end{tabular}

BMI, body mass index; PU, periumbilical; TU, transumbilical; TA, transabdominal. 
the short-term, reporting an excess weight loss of $32.1 \%$ (range, $26.0 \%-37.4 \%) .{ }^{45}$ Other intragastric balloons have been developed over the years and the less invasive nature of this technique is appealing to many patients, causing it to be an area of exploration and interest.

\section{Endoscopic sleeve gastroplasty}

Similar to laparoscopic SG, endoscopic sleeve gastroplasty is a technique that reduces the gastric volume. A U.S. Food and Drug Administration-approved endoscopic suturing device (OverStitch Endoscopic Suturing System, Apollo Endosurgery) is entered transorally to create a full-thickness suture from the antrum to the cardia in the greater curvature side (Fig. 4). ${ }^{46}$ In one study, four patients with uncomplicated BMI between $30 \mathrm{~kg} / \mathrm{m}^{2}$ and $40 \mathrm{~kg} / \mathrm{m}^{2}$

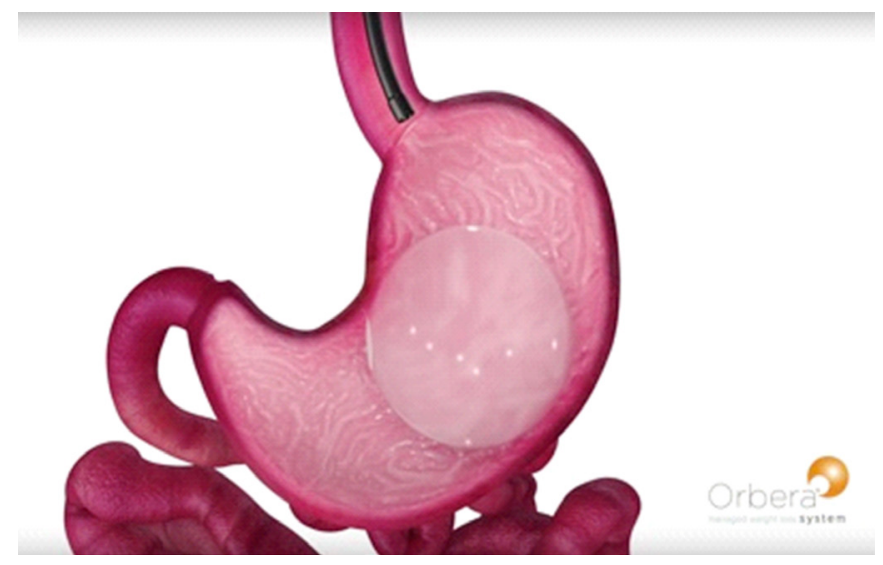

Figure 3. The Orbera intragastric balloon (Apollo Endosurgery, San Diego, CA, USA).

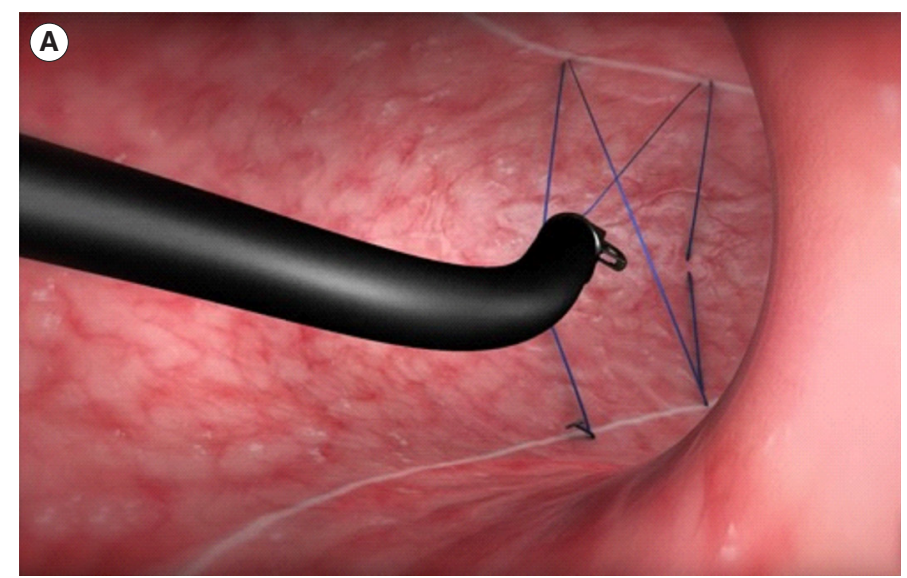

underwent the procedure, and the reported operating time was 172 to 245 minutes. The Primary Obesity Surgery Endolumenal (POSE) procedure is also an endoscopic gastroplasty technique that uses specific instruments to place suture anchors at the gastric fundus and antrum to decrease fundal volume and cause delayed gastric emptying. It uses the g-Cath EZ delivery catheter with Snowshoe Suture Anchors (USGI Medical, San Clemente, CA, USA) delivered through a specialized endoscopic device (Fig. 5). A study of 147 patients with a mean BMI of $38.0 \pm 4.8 \mathrm{~kg} / \mathrm{m}^{2}$ who underwent the POSE procedure, at a follow-up of 1 year, showed an excess weight loss of $45 \%$ and an average of $15 \%$ reduction in total weight. ${ }^{47}$ Novel procedures are being reported in this area; however, large cohort results and long-term data remain lacking and are thus an area of consideration.

\section{EndoBarrier}

The EndoBarrier Gastrointestinal Liner (GI Dynamics, Lexington, MA, USA) is an endoscopically inserted impermeable sleeve made of Teflon (Chemours Company, Wilmington, DE, USA) that creates an malabsorptive duodenojejunal bypass (Fig. 6A). Once inserted up to the duodenal bulb, it is extended toward the proximal jejunum, allowing for food material to bypass the duodenum without meeting the digestive juices (Fig. 6B). Schouten et al. ${ }^{48}$ performed a randomized trial involving 30 patients in an EndoBarrier group and 11 patients in a control group. Weight loss in the EndoBarrier group was significantly higher as compared with that in the control group $(19.0 \%$ vs. $6.9 \%, P<0.002)$ and no proce-

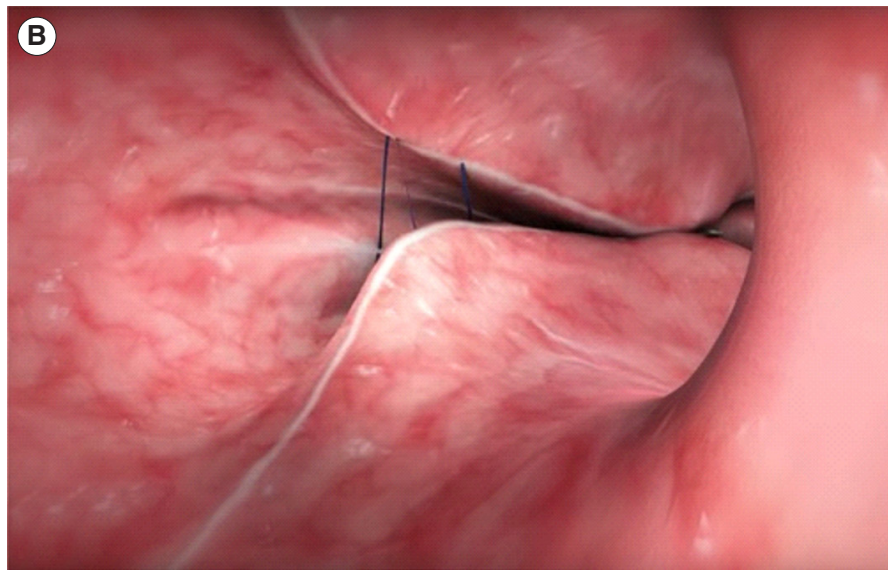

Figure 4. Endoscopic sleeve gastrectomy using the OverStitch Endoscopic Suturing System (Apollo Endosurgery, San Diego, CA, USA). (A) An endoscopic suturing device is used to create full-layer sutures in the greater curvature of the stomach. (B) This gastroplasty technique reduces intragastric volume. 

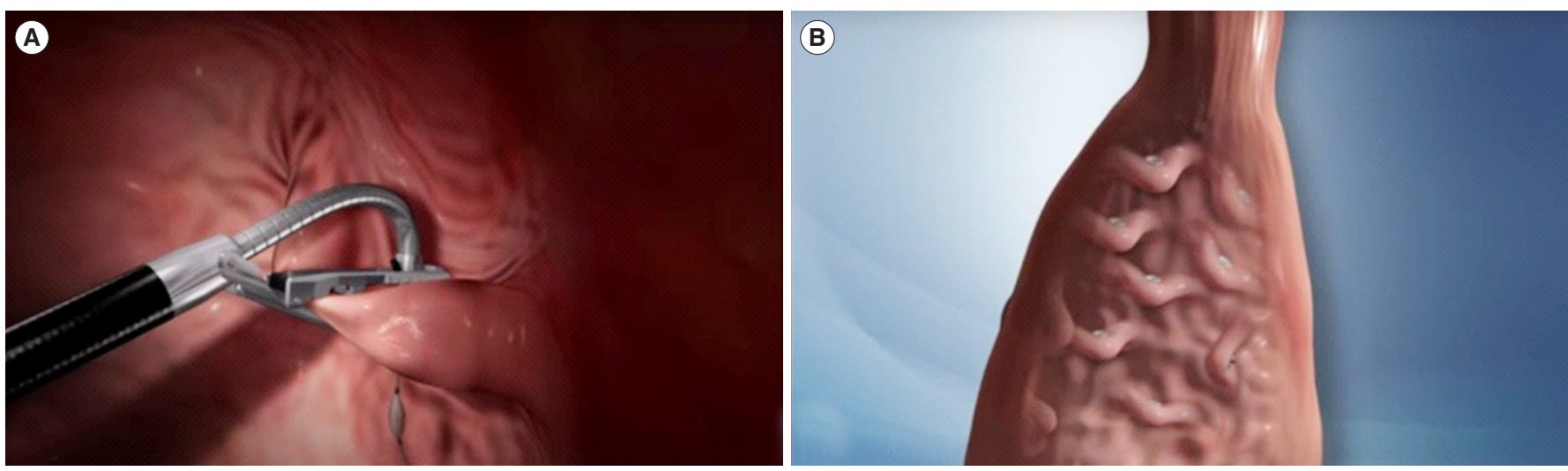

Figure 5. The Primary Obesity Surgery Endolumenal (POSE) procedure. (A) Snowshoe Suture Anchors (USGI Medical, San Clemente, CA, USA) are introduced using specialized catheters. (B) Intermittent placement of the sutures reduces intragastric volume.
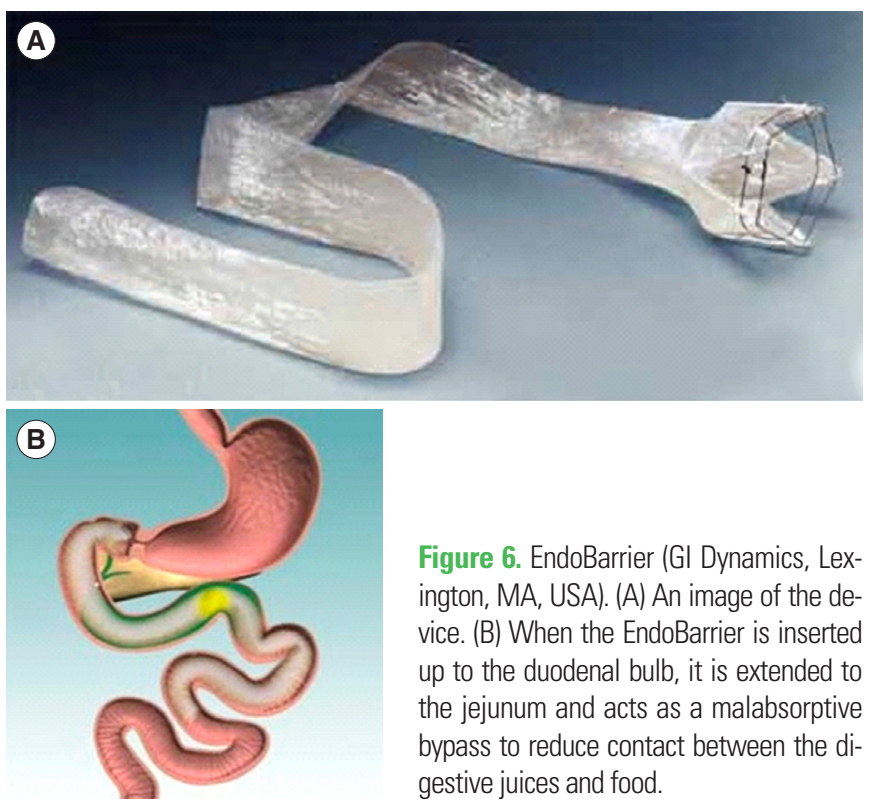

Figure 6. EndoBarrier (GI Dynamics, Lexington, MA, USA). (A) An image of the device. (B) When the EndoBarrier is inserted up to the duodenal bulb, it is extended to the jejunum and acts as a malabsorptive bypass to reduce contact between the digestive juices and food.

dure-related adverse events were found. A meta-analysis of 15 studies including five randomized trials also noted a significant degree of weight loss associated with EndoBarrier use (GI Dynamics), but no difference in glycemic control. ${ }^{49}$ More long-term studies are needed to fully evaluate this device's potency and safety.

\section{SUMMARY}

Morbid obesity was once considered to be a contraindication for laparoscopic surgery but, with the increasing application of bariatric surgery for metabolic diseases, the mean BMI of patients undergoing these surgeries is decreasing, making the application of novel minimally invasive techniques more feasible. In this review, we have listed some of the most popular LESS bariatric surgeries being performed throughout the world and explored their efficacies and applications.

\section{Indication and benefits of LESS in bariatric patients}

Good patient selection and adequately defining the indications for single-port bariatric surgery are important concerns to ensure patient safety and the success of the procedure. In some literature, BMI of more than $50 \mathrm{~kg} / \mathrm{m}^{2}$, height of more than $180 \mathrm{~cm}$, and xiphoid-umbilicus distance of more than $20 \mathrm{~cm}$ have been mentioned as unsuitable criteria for single-port bariatric surgery. ${ }^{8,11}$ Patel et al. $^{37}$ commented on the possible need of an additional port placement in male patients for SP-AGB. To date, most of the candidates in single-port bariatric surgery have been female, and Sucher et al. ${ }^{39}$ attributes this to the shorter height and smaller left liver of female patients. With the scope of bariatric surgery now broadened to cover metabolic diseases as well as obesity, the average BMI of suitable patients is decreasing. In our department, we recommend that single-port techniques be performed in patients with BMI of less than $50 \mathrm{~kg} / \mathrm{m}^{2}$, regardless of sex.

The current consensus in laparoscopic bariatric surgery is heading towards SG. SG is more feasible and has a lower learning curve as compared with RYGB. ${ }^{50,51} \mathrm{~A}$ randomized trial by Karamanakos et al. ${ }^{52}$ of 16 patients in each arm showed a higher degree of excess weight loss and appetite suppression in the SG group versus in the RYGB group. Though more studies with larger patient cohorts are needed to fully compare the efficacies of these two popular proce- 
dures, the feasibility, safety, and effectiveness of SG makes it an appealing candidate for the widespread application of single-port techniques. Our institution selects SPSG as the first choice of procedure in obese patients. Patients with BMI of more than $50 \mathrm{~kg} / \mathrm{m}^{2}$ and those with comorbidities such as uncontrolled diabetes mellitus are also given other options to consider.

Confidentiality also leads to patient confidence. Whenever possible, SILS is best done in a transumbilical fashion to achieve great results in terms of cosmesis and patient satisfaction. Lakdawala et al. ${ }^{31}$ provided a scar satisfaction score to quantify patient satisfaction with the visibility of the surgical wound. Most obese patients have lower self-esteem and having better cosmesis, such as having no obvious signs of surgery at all, may lead to better motivation and quality of life.

\section{Technical concerns of LESS}

The performance of SILS is technically difficult due to limitations in the operator's range of motion, collision of the instruments, and unstable field of view. To overcome these obstacles, first, liver retraction should be done sufficiently. Several techniques report various liver retraction methods, but we prefer the suture retraction method due to the fact that it does not require an additional incision and it effectively and safely retracts the left lobe of the liver upwards. ${ }^{15}$ Secondly, we use a scope holder to stabilize the camera and reduce collisions between the operator's and scopist's arms. The procedure is generally done safely without prolongation of the operation time. ${ }^{9}$ Although the advancements in laparoscopic surgery have been exceptional, more tools must be developed and tested to allow for LESS bariatric surgery to be more readily employed throughout institutions.

There is a major concern regarding the onset of incisional hernia in single-incision surgery. Port-site hernia rates are reported to be as high as $5.8 \%$ in single-incision cholecystectomy, and high BMI $\left(\geq 30 \mathrm{~kg} / \mathrm{m}^{2}\right)$ is a known risk factor for incisional hernia. ${ }^{53-55}$ However, it's worth noting that, in the prospective study by Lakdawala et al. ${ }^{31}$ mentioned previously, only three patients (1\%) in the SPSG group had incisional hernia-a much lower rate than that expected. Long-term evidence regarding the presentation of port-site hernia after LESS bariatric surgery is still lacking and, hence, careful measures must be taken during the closure of the wound.

\section{CONCLUSION}

With the prior and ongoing technological innovations in minimally invasive surgery, the era of LESS in bariatric surgery has commenced. Several cases of single-port bariatric surgery have been reported in the literature, with the performance of SPSG as the leading trend. Various endoscopic techniques have also been employed, but still require further controlled studies to fully assess their usefulness. Currently, it can be said that LESS appears to be a safe and applicable method in patients requiring bariatric surgery. More attempts to apply LESS in bariatrics may allow for the buildup of additional long-term data regarding its use.

\section{CONFLICTS OF INTEREST}

The authors declare no conflict of interest.

\section{ACKNOWLEDGMENTS}

The authors give their thanks to Apollo Endosurgery, USGI Medical, and GI Dynamics for their permission to use photos of their products.

\section{REFERENCES}

1. Schauer PR, Bhatt DL, Kirwan JP, Wolski K, Aminian A, Brethauer SA, et al. Bariatric surgery versus intensive medical therapy for diabetes: 5-year outcomes. N Engl J Med 2017; 376:641-51.

2. Angrisani L, Santonicola A, Iovino P, Formisano G, Buchwald H, Scopinaro N. Bariatric surgery worldwide 2013. Obes Surg 2015;25:1822-32.

3. Picot J, Jones J, Colquitt JL, Gospodarevskaya E, Loveman E, Baxter L, et al. The clinical effectiveness and cost-effectiveness of bariatric (weight loss) surgery for obesity: a systematic review and economic evaluation. Health Technol Assess 2009; 13:1-357.

4. Belachew M, Legrand MJ, Defechereux TH, Burtheret MP, Jacquet N. Laparoscopic adjustable silicone gastric banding in the treatment of morbid obesity: a preliminary report. Surg 
Endosc 1994;8:1354-6.

5. Baltasar A, Serra C, Pérez N, Bou R, Bengochea M, Ferri L. Laparoscopic sleeve gastrectomy: a multi-purpose bariatric operation. Obes Surg 2005; 15:1124-8.

6. Himpens J, Dobbeleir J, Peeters G. Long-term results of laparoscopic sleeve gastrectomy for obesity. Ann Surg 2010;252: 319-24.

7. Saber AA. Reduced port laparoscopic bariatric surgery. In: Agrawal S, editor. Obesity, bariatric and metabolic surgery: a practical guide. Cham: Springer International Publishing; 2016. p. 335-41.

8. Huang CK. Single-incision laparoscopic bariatric surgery. J Minim Access Surg 2011;7:99-103.

9. Kang SH, Lee Y, Park YS, Ahn SH, Park DJ, Kim HH. Solo single-incision laparoscopic resectional Roux-en-Y gastric bypass for morbid obesity with metabolic syndrome. Obes Surg 2017;27:3314-9.

10. Gill IS, Advincula AP, Aron M, Caddedu J, Canes D, Curcillo PG 2nd, et al. Consensus statement of the consortium for laparoendoscopic single-site surgery. Surg Endosc 2010;24:762-8.

11. Moreno-Sanz C, Morandeira-Rivas A, Sedano-Vizcaino C, Tenías-Burillo JM, Román-Ortíz C, de la Espada JB. Single-incision laparoscopic bariatric surgery: a systematic review. Surg Obes Relat Dis 2015;11:248-57.

12. Nisky I, Huang F, Milstein A, Pugh CM, Mussa-Ivaldi FA, Karniel A. Perception of stiffness in laparoscopy: the fulcrum effect. Stud Health Technol Inform 2012;173:313-9.

13. Huang CK, Yao SF, Lo CH, Houng JY, Chen YS, Lee PH. A novel surgical technique: single-incision transumbilical laparoscopic Roux-en-Y gastric bypass. Obes Surg 2010;20:1429-35.

14. Saber AA, El-Ghazaly TH, Dewoolkar AV, Slayton SA. Singleincision laparoscopic sleeve gastrectomy versus conventional multiport laparoscopic sleeve gastrectomy: technical considerations and strategic modifications. Surg Obes Relat Dis 2010; 6:658-64.

15. Shabbir A, Lee JH, Lee MS, Park DJ, Kim HH. Combined suture retraction of the falciform ligament and the left lobe of the liver during laparoscopic total gastrectomy. Surg Endosc 2010;24:3237-40.

16. Nguyen NT, Hinojosa MW, Smith BR, Reavis KM. Single laparoscopic incision transabdominal (SLIT) surgery-adjustable gastric banding: a novel minimally invasive surgical approach. Obes Surg 2008;18:1628-31.

17. Schwack BF, Novack R, Youn H, Fielding CR, Kurian MS, Fielding GA. Single-incision laparoscopic adjustable gastric banding is effective and safe: 756 cases in an academic medical center. Obes Surg 2013;23:332-7.

18. Nguyen NT, Slone J, Reavis K. Comparison study of conventional laparoscopic gastric banding versus laparoendoscopic single site gastric banding. Surg Obes Relat Dis 2010;6:503-7.

19. Chevallier JM, Zinzindohoué F, Douard R, Blanche JP, Berta JL, Altman JJ, et al. Complications after laparoscopic adjustable gastric banding for morbid obesity: experience with 1,000 patients over 7 years. Obes Surg 2004;14:407-14.

20. Suter M, Calmes JM, Paroz A, Giusti V. A 10-year experience with laparoscopic gastric banding for morbid obesity: high long-term complication and failure rates. Obes Surg 2006;16: 829-35.

21. Angrisani L, Santonicola A, Iovino P, Vitiello A, Zundel N, Buchwald $\mathrm{H}$, et al. Bariatric surgery and endoluminal procedures: IFSO worldwide survey 2014. Obes Surg 2017;27: 2279-89.

22. Lee JH, Ahn SH, Son SY, Lee CM, Park DJ, Kim HH. Comparison of changes in gastrointestinal hormones after conventional Roux-en Y gastric bypass versus near total gastrectomy with Roux-en Y gastric bypass in diabetes and obesity rat model. J Metab Bariatr Surg 2012;1:55-60.

23. Schauer PR, Bhatt DL, Kirwan JP, Wolski K, Brethauer SA, Navaneethan SD, et al. Bariatric surgery versus intensive medical therapy for diabetes: 3-year outcomes. N Engl J Med 2014; 370:2002-13.

24. Saber AA, El-Ghazaly TH, Minnick DB. Single port access transumbilical laparoscopic Roux-en-Y gastric bypass using the SILS port: first reported case. Surg Innov 2009;16:343-7.

25. Doulamis IP, Economopoulos KP. Transumbilical Roux-en-Y gastric bypass in morbidly obese patients: a systematic review. Int J Surg 2015;20:153-7.

26. Higa KD, Boone KB, Ho T. Complications of the laparoscopic Roux-en-Y gastric bypass: 1,040 patients. What have we learned? Obes Surg 2000;10:509-13. 
27. Marshall JS, Srivastava A, Gupta SK, Rossi TR, DeBord JR. Roux-en-Y gastric bypass leak complications. Arch Surg 2003; 138:520-3.

28. Gaillard M, Tranchart H, Lainas P, Ferretti S, Perlemuter G, Dagher I. Single-port laparoscopic sleeve gastrectomy as a routine procedure in 1,000 patients. Surg Obes Relat Dis 2016; 12:1270-7.

29. Lo C, Latin L, Fariñas Á, Cruz Pico CX, Postoev A, Ibikunle $\mathrm{C}$, et al. Does single-port laparoscopic sleeve gastrectomy result in improved short-term perioperative outcomes compared to conventional multi-port laparoscopic sleeve gastrectomy? Int J Surg 2015;22:67-71.

30. Pourcher G, Di Giuro G, Lafosse T, Lainas P, Naveau S, Dagher I. Routine single-port sleeve gastrectomy: a study of 60 consecutive patients. Surg Obes Relat Dis 2013;9:385-9.

31. Lakdawala M, Agarwal A, Dhar S, Dhulla N, Remedios C, Bhasker AG. Single-incision sleeve gastrectomy versus laparoscopic sleeve gastrectomy: a 2-year comparative analysis of 600 patients. Obes Surg 2015;25:607-14.

32. Park YS, Park DJ, Kim KH, Park DJ, Ahn SH, Kim HH. Single incisional laparoscopic sleeve gastrectomy and adolescent bariatric surgery: case report and brief review. J Metab Bariatr Surg 2015;4:40-5.

33. Scopinaro N, Marinari GM, Camerini G. Laparoscopic standard biliopancreatic diversion: technique and preliminary results. Obes Surg 2002;12:362-5.

34. Tacchino RM, Greco F, Matera D. Single-incision laparoscopic biliopancreatic diversion. Surg Obes Relat Dis 2010;6:444-5.

35. Teixeira J, McGill K, Binenbaum S, Forrester G. Laparoscopic single-site surgery for placement of an adjustable gastric band: initial experience. Surg Endosc 2009;23:1409-14.

36. Raman SR, Franco D, Holover S, Garber S. Does transumbilical single incision laparoscopic adjustable gastric banding result in decreased pain medicine use? A case-matched study. Surg Obes Relat Dis 2011;7:129-33.

37. Patel AG, Murgatroyd B, Ashton WD. Single incision laparoscopic adjustable gastric banding: 111 cases. Surg Obes Relat Dis 2012;8:747-51.

38. Pitot D, Takieddine M, Abbassi Z, Agrafiotis A, Bruyns L, Ceuterick M, et al. Pure transumbilical SILS gastric bypass with mechanical circular gastrojejunal anastomosis feasibility. Surg Endosc 2014;28:3007-11.

39. Sucher R, Resch T, Mohr E, Perathoner A, Biebl M, Pratschke $\mathrm{J}$, et al. Single-incision laparoscopic sleeve gastrectomy versus multiport laparoscopic sleeve gastrectomy: analysis of 80 cases in a single center. J Laparoendosc Adv Surg Tech A 2014;24: 83-8.

40. Morales-Conde S, Rubio-Manzanares Dorado M, Barranco A, Alarcón I, Pereira JL, García-Luna PP, et al. Single-port Rouxen-Y gastric bypass: toward a less invasive procedure with the same surgical results and a better cosmesis. Surg Endosc 2013; 27:4347-53.

41. Fernández JI, Ovalle C, Farias C, de la Maza J, Cabrera C. Transumbilical laparoscopic Roux-en-Y gastric bypass with hand-sewn gastrojejunal anastomosis. Obes Surg 2013;23:140-4.

42. Nieben OG, Harboe H. Intragastric balloon as an artificial bezoar for treatment of obesity. Lancet 1982;1:198-9.

43. ASGE Bariatric Endoscopy Task Force; ASGE Technology Committee, Abu Dayyeh BK, Edmundowicz SA, Jonnalagadda S, Kumar N, et al. Endoscopic bariatric therapies. Gastrointest Endosc 2015;81:1073-86.

44. Genco A, Bruni T, Doldi SB, Forestieri P, Marino M, Busetto L, et al. BioEnterics intragastric balloon: the Italian experience with 2,515 patients. Obes Surg 2005;15:1161-4.

45. Imaz I, Martínez-Cervell C, García-Alvarez EE, Sendra-Gutiérrez JM, González-Enríquez J. Safety and effectiveness of the intragastric balloon for obesity: a meta-analysis. Obes Surg 2008; 18:841-6.

46. Abu Dayyeh BK, Rajan E, Gostout CJ. Endoscopic sleeve gastroplasty: a potential endoscopic alternative to surgical sleeve gastrectomy for treatment of obesity. Gastrointest Endosc 2013;78:530-5.

47. López-Nava G, Bautista-Castaño I, Jimenez A, de Grado T, Fernandez-Corbelle JP. The Primary Obesity Surgery Endolumenal (POSE) procedure: one-year patient weight loss and safety outcomes. Surg Obes Relat Dis 2015;11:861-5.

48. Schouten R, Rijs CS, Bouvy ND, Hameeteman W, Koek GH, Janssen IM, et al. A multicenter, randomized efficacy study of the EndoBarrier Gastrointestinal Liner for presurgical weight loss prior to bariatric surgery. Ann Surg 2010;251:236-43. 
49. Rohde U, Hedbäck N, Gluud LL, Vilsbøll T, Knop FK. Effect of the EndoBarrier gastrointestinal liner on obesity and type 2 diabetes: a systematic review and meta-analysis. Diabetes Obes Metab 2016;18:300-5.

50. Zacharoulis D, Sioka E, Papamargaritis D, Lazoura O, Rountas $\mathrm{C}$, Zachari E, et al. Influence of the learning curve on safety and efficiency of laparoscopic sleeve gastrectomy. Obes Surg 2012;22:411-5.

51. Schauer P, Ikramuddin S, Hamad G, Gourash W. The learning curve for laparoscopic Roux-en-Y gastric bypass is 100 cases. Surg Endosc 2003;17:212-5.

52. Karamanakos SN, Vagenas K, Kalfarentzos F, Alexandrides TK. Weight loss, appetite suppression, and changes in fasting and postprandial ghrelin and peptide-YY levels after Roux-en$\mathrm{Y}$ gastric bypass and sleeve gastrectomy: a prospective, double blind study. Ann Surg 2008;247:401-7.

53. Alptekin H, Yilmaz H, Acar F, Kafali ME, Sahin M. Incisional hernia rate may increase after single-port cholecystectomy. J Laparoendosc Adv Surg Tech A 2012;22:731-7.

54. Julliard O, Hauters P, Possoz J, Malvaux P, Landenne J, Gherardi D. Incisional hernia after single-incision laparoscopic cholecystectomy: incidence and predictive factors. Surg Endosc 2016;30:4539-43.

55. Buckley FP 3rd, Vassaur HE, Jupiter DC, Crosby JH, Wheeless CJ, Vassaur JL. Influencing factors for port-site hernias after single-incision laparoscopy. Hernia 2016;20:729-33. 